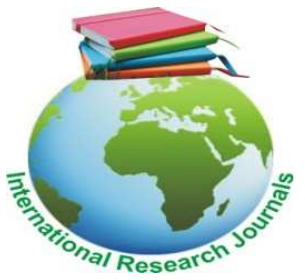

African Journal of Food Science and Technology (ISSN: 2141-5455) Vol. 8(5) pp. 081-084, July, 2017

DOI: http:/dx.doi.org/10.14303/ajfst.2017.089

Available online @http://www.interesjournals.org/AJFST

Copyright (C2017 International Research Journals

Review

\title{
Trends in Sausage Production
}

\author{
Akpan, I. P \\ Department of Animal Science, University of Uyo \\ Corresponding Author's Email: idyphil@gmail.com
}

\begin{abstract}
Sausage production in the olden days was a way of preserving meat but in modern days, it has gradually reshaped into meat product with addition of ingredients other than salt. There has been tremendous improvement in almost all aspects of Sausage production such as Shape of the product, species of animals used, casings, ingredients, equipment and machines etc. further advances will still be made in sausage production due to revolution of technology even in areas that have been addressed and the ones that are yet to be researched. This paper goes forth to bring to full knowledge the trends in sausage production.
\end{abstract}

Key words: Sausage production, meat products, processing, processed meat, comminuted meat

\section{INTRODUCTION}

Sausage is derived in the latin word 'Salsus' meaning salted or preserved by salting('Sausage making', 2009) or 'Salsicia' meaning something salted. The term was probably originally applied to cured or salted meat generally. In the olden days, there were no refrigerators for meat preservation and sausage making was a way to solve this problem. Sausage has been an age long method of preservation as recorded by the primitive man, the ancient Egyptians and American Indians (Ikeme, 1990). The first recognizable mention of this meat food is found in a greek play called 'The Orya' or 'The Sausage' written about 500 B.C. Thereafter, the word Sausage occurs with frequency in Greek writings such as in the 'Odyssey' written by Homer in 830 B.C.

Sausage making evolved as an effort to economize and preserve meat which could not be consumed immediately after slaughter (Marchello et al., 1998). This practise could be traced back to the ancient Greeks and Romans who made sausages which were usually plain and unspiced ('Sausage', 2008). In the middle age, people started developing sausages with spices which led to modern Sausage.

Different types of sausages were created all over the world and each region developed their own distinctive style of sausage influenced by availability of local ingredients, spices casings and climate. Regions with distinct seasons used different techniques to preserve meat. In the cold seasons, fresh sausage was able to keep for short periods of time without refrigeration. The smoking process was developed to preserve sausages in warmer seasons.
Most of the famous sausages made were named after the locality from which they were first made: the Frankfurter in Frankfurt, Germany; the bologna in Bologna, Italy; the genoa salami in Genoa, Italy; Lyons sausage from Lyons, France and Berliner sausage from from Berlin Germany. In England, sausages became associated with the county - Berkshire, Wiltshire, Lincolnshire, Cumberland etc. ('Sausage', 2008)

Sausages are meat products that are comminuted, mixed with other ingredients and stuffed in a casing.

\section{Classification of sausage}

The classification method for Sausage is according to the methods of processing or manufacture. Sausage is basically classified into two broad groups: Raw and heat processed sausages. Raw sausages are further subdivided into two categories: fresh and fermented sausages. Then the fermented are further sub-divided into Dry and Semi-dry. Similarly, the heat processed are sausages on the other hand are classified into Uncooked smoked sausages, cooked smoked sausages and cooked sausages.

a. Fresh sausages are made from fresh meats which are as a rule, neither cured, smoked, fermented nor cooked. Fresh sausages must be kept under refrigeration prior to eating. They are heated by the consumer before serving e.g Fresh pork, Breakfast, sausage, Italian sausage, Fresh chorizo. 
082 Afr. J. Food Sci. Technol.

b. Fermented sausages are made from cured or uncured, non- fermented and often smoked meats but they are not heat processed in anyway. These sausages have a distinctive tangy flavour due to the presence of lactic acid that is produced by fermentation. The meat is stuffed into casing and allowed to 'ferment', the process by which bacteria metabolize sugars and produce acids and other compounds as by products. In meat fermentation, bacteria which produce lactic acid are utilized to produce the tangy flavour of dry sausages. They are sometimes referred to as 'summer sausages' and eaten cold e.g Genoa, Salami, Pepperoni, Frizzes, Lebanon bologna Cevelat, Thuringer, Mortadella.

c. Uncooked smoked sausages are mostly cured, nonfermented products, their shelf-life is increased by heating due to partial reduction of their moisture content; they are usually finally cooked before consumption. E.g. Kielbasas (Polish sausage), Chinese sausage, mettwurst, teawurst, smoked country-styled pork sausage.

d. Cooked smoked sausages may be cured or uncured, are heat processed and sometimes smoked. They often contain a variety meat or organ meat such as liver. As ready to eat product, cooked sausages are usually served cold and may be stored refrigerated for up to seven days after opening a package. E.g. Franfurters, Cotto salami, Berliner.

e. Cooked sausages are ready-to-serve products, basically made from previously cooked fresh or exceptionally cured raw materials, subjected to final cooking after stuffing without additional smoking e.g Liverswurst, Braunschweiger, blood sausage.

f. Specialty sausages: this class of sausage is not specific about the method of processing. It is a diverse category that may contain cured, uncured, smoked and non-smoked meats thatdo not readily fit into other category. They are seasoned and often formed into loaves. E.g Olive loaf, head cheese, jellied corned beef, scrapple souse, sausage rolls

\section{Advances in technology of sausage production}

Sausage production has been in existence for twenty centuries ('Sausage History', 2008) and over the years, there are some modifications in almost all areas of production although the principles remain the same. With the advent of civilization and evolution of technology, there has been improvement in the following areas:

1. Species of animal: The species of animal used for sausage production traditionally were pork, beef and veal if the cost could be procured. Recently, species of animal being used include turkey (poultry), venison, and fish. The most recent is the use of African Catfish (Clarias gariepinus, Burchell 1822) (Oksuz, 2008) in the production of dry sausage.

2. Shape of the product: sausages were traditionally formed symmetrically but today they come in different shapes, sizes and forms to meet the consumers' appeal. Example is the Daisy-shaped slice of Deli product, frankfurters etc.

\section{Casing:}

a. Natural casings are being preserved in packages for future use (Casing expert, 2003). These natural casings are preserved in salt. It must be soaked in warm water before use.

b. Special grade smooth polyethene is now in use for sausage casing as these can take print and permit an attractive presentation (Savic, 1985), also plastic casing that can withstand the automated processes and tight packaging are also available commercially.

c. Cellulose casing with antimicrobial system are developed for effective reduction of the risk of Listeria monocytogenes surface contamination of hot Dogs and other cooked sausage (Hasen, 2006). The invention involves application of a natural antimicrobial system to a sausage surface via the cellulose casing. After cooking and peeling away the casing, the resultant surface treatment on the hot Dog or sausage demonstrates the definite killing of Listeria within the first few hours of package life, thus providing an effective safeguard in the event of a post-processing contamination episode.

d. Co-extruded casing have also been introduced which uses collagen and Alginate as the casing materials. It allows continuous production without interruption in casing loading (Sam, 2006).

e. Liquid form casing is an alginate based casing which applies casing in liquid form and then sets it in a second solution.It encases both ends of the sausage and is taste and texture natural. The advantage of this casing is that it can take both taste and colour profile in the liquid state, offering producers more several options including 'smoked'. An example of this casing is Vegicase ${ }^{\mathrm{TM}}$

\section{New Equipment}

a. Use of Humidity Monitoring Devices (HMD): use of HDM as against the use of dry and wet bulb thermometers for the purpose of measuring relative humidity in dry sausage manufacture. Humidity monitoring devices give a direct readout of relative humidity.

b. Automation of sausage production: machines are now used at each step of production as against the use of manual labour and implement. ('Sausage Source',2007). The Sausage industry has seen a vast improvement in product integrity, particle definition, texture and yield due to evolution of vacuumization in pumps, inline grinding, automatic hanging devices, automated mold loading, scalding and batching systems and computer controlled product flow e.g the AL series of machines produced by handtmann for linking natural sausage casing to exact length and weight. Year in year out, new models of these machines are being manufactured such as grinders with different plate diameter and holes for desired particle size. The use of 
a. mechanical stuffers have also replaced the used of animal horns such as cattle horns (Savic, 1985) thereby reducing drudgery in stuffing process.

b. Sausage formulation software: development of sausage formulation software has made the cumbersome sausage formulation calculations easy and fast for the sausage processors. An example is the SausageMania ${ }^{\circledR}$ spreadsheet.

\section{Ingredients}

a. Introduction of Starter cultures: Starter cultures are commercial preparation containing living or resting GRAS (Generally Regard As Safe) micro- organisms that develop the desired metabolic activity in the food. Traditionally, fermented sausages were made with the aid of spontaneous micro- organisms in the environment. The idea of inoculating Lactobacillus into dry fermented sausage was introduced by Jensen and Paddock in 1940 (Errkkila, 2001). The use of starter cultures in the manufacture of dry fermented sausage, such as pepperoni and summer sausagehas achieved controlled fermentation that ensures and enhances the production of desired end product (Bacus, 1984; Leistner, 1992). Lactobacillus plantarum and Pediococcus acidilactici are used to ferment the added sugars and produce lactic acid, which decreases the $\mathrm{pH}$ of the product. This helps to make the product shelf-stable and provides unique flavours and textures.Commercial Starter cultures with strains of Pediococcus acidilactici, Lactobacillus curvatus, Staphylococcus xylosushave also been produced such as the BLESSING biotech GmbH (JÖrg Groth, 2008).

b. Use of acidulants: These are chemicals used in place of starter cultures to eliminate fermentation in fermented sausages. They are usually encapsulated acids or slow release Glucono-Delta- Lactone (GDL). Encapsulated acids are tiny beads of acid surrounded by lipid coat. They are mixed into the batter and at $135^{\circ} \mathrm{F}$, the lipid coat melts and releases the acid.

c. Use of Bioprotectants: Bioprotectants are microorganism which prevent growth of unwanted microorganisms by producing in addition Lactic acid other antimicrobial compounds. Bioprotectant products are derived from Propionibacterium freudenrei sub sp. shermanii. It contains organic acid diacetyl and low molecularweight polypeptide e.g MicrogardTM510 and MicrogardTM 300. Bioprotectant improves the quality of sausage by controlling microbial growth during storage (Dhamankar et al., 2007).

\section{New product development}

a. Pork and egg sausage: A new sausage type product made of pork and egg white has been developed in Japan (Tanabe, 2003). This new tasty emulsion-type pork sausage was prepared by using specific combinations of flavoured meats, food additives and cookery arts which is firmly rooted in Japan diet. The ingredients of the new pork product are $200 \mathrm{~g}$ ham of Japan-pork cut, $10 \mathrm{~g}$ egg white powder whipped until foamy in $70 \mathrm{~g}$ water, 5 or $2.5 \mathrm{~g} \mathrm{NaCl}, 4 \mathrm{~g}$ fresh ginger juice, $40 \mathrm{~g}$ potato starch, and $190 \mathrm{~g}$ water.

b. Meatless sausage: soy-based sausage rich in isoflavones, which helps to prevent cancer and heart diseases have been developed by the Food and Nutrition Research Institute of the Department of Science and Technology, Philippines, for sausage lovers who for health reasons cannot eat meat sausage.(DOST- FNRI, 2008).

\section{CONCLUSION}

Although sausage making has had a long and colourful history, several recent developments have been possible only because of the processing knowledge gained over the years. While some of its basic practices are as old as civilization, the industry is constantly adopting new developments in processing in the light of later scientific and technical knowledge. There is every reason to believe that in the coming years, further advances will still be made in sausage production due to revolution of technology even in areas that have been addressed and the ones that are yet to be researched.

\section{REFERENCES}

Bacus J(1984). Dry and semi dry sausages. In Utilization of microorganisms in meat processing. The Handbook for meat plant operators (pp. 15- 56). Letchworth, England, Uk: Research studies Press.

Casing export, (2003). Natural casing production www.Casingexport.com. Retrieved December 14, 2008.

Dhamankar N, Clarke AD(2007). Effect of Bioprotectants in Turkey sausage. 60th Annual Reciprocal Meat conference. June 17-20, 2007. Brookings, South Dakota. www.meatscience.org. Retrieved October 20, 2008.

DOST- FNRI, (2008).DOST -FNRI develops new meatless sausage. http://region4a.dost.gov.ph/index.php?option.com. Retrieved December 14, 2008

Erkkila S(2001). Bioprotective and probiotic meat starter culture for the fermentation of sausages. Academic Dissertation. Helsinki, Finland.

Groth J(2008). BLESING Biotech: Starter culture for tasty food. www.bio-pro.de/en/life/ wissencharf/index.

Hasen C(2006). About meat starter culture F- LC www.butcherpacker.com. Retrieved Jan 11, 2009.

Leistner $F(1992)$. The essentials of producing stable and safe raw fermented sausages. In F. J. M. Smulders, F. Toldra, J. Flores, \& M. Prieto (Eds), News technologies for meat and meat products (pp 119) Utrecht, the Netherlands: ECCEAMST, Audet Tud - schreen, B.V.

Marchello M, Garden-Robinson J(1995). The Art and Practice of Sausage Making. NDSU Extension service. North Dakota State University, Fargo, North Dakota.

Oksuz A, Akdemir E, Gulsun C, Muzaffer S, Ozeren A(2008). International Journal of Food Science and Technology, vol 43, No1, Jan, 2008, pp166-172 (7). Blackwell Publishers. www.ingentaconnect.comSaavic IV(1985). Small scale sausage production. Food and Agriculture Organization of the United Nations, Rome. M- 72 ISBN92-5-1021187-2 
084 Afr. J. Food Sci. Technol.

Sam G(2006). $21^{\text {st }}$ century sausages: the age-old tradition of sausage manufacturing is benefiting from new technologies. The national provioner. www.allbusiness.com

Sausage (2008). The Columbia Encylopedia, sixth edition. Retrieved
January
15,2009
from
Encyclopedia.com

Sausage making (2009). Wilkipedia, the free encyclopedia from www.wikimedia.org. retrieved January 18,2009.

Tanabe $\mathrm{H}(2003)$ Development of a new sausage-type product with pork and egg white. Final Reports for Research Grants for Meat and http://encyclopedia.com/doc/1E1- sausage.htm.

Meat Products 21, 211-215. 